\title{
MR Imaging Features of Anaplastic Pleomorphic Xanthoastrocytoma Mimicking High-Grade Astrocytoma
}

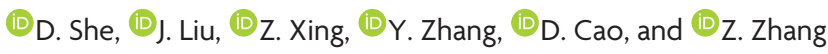

\begin{abstract}
BACKGROUND AND PURPOSE: Anaplastic pleomorphic xanthoastrocytoma, which has been recently defined as a distinct entity in the 2016 World Health Organization classification, may exhibit aggressive clinical behavior and relatively worse prognosis than pleomorphic xanthoastrocytoma. This study aimed to investigate whether there were any differences in MR imaging characteristics between these 2 tumors.
\end{abstract}

MATERIALS AND METHODS: This retrospective study included 9 patients with anaplastic pleomorphic xanthoastrocytoma and 10 patients with pleomorphic xanthoastrocytoma who underwent MR imaging before an operation. DWI was performed in 17 patients (8 with anaplastic pleomorphic xanthoastrocytoma, 9 with pleomorphic xanthoastrocytoma); and DSC-PWI, in 9 patients (5 with anaplastic pleomorphic xanthoastrocytoma, 4 with pleomorphic xanthoastrocytoma). Demographics, conventional imaging characteristics (location, size, cystic degeneration, enhancement, peritumoral edema, and leptomeningeal contact), minimum relative ADC ratio, and maximum relative CBV ratio were evaluated between the anaplastic pleomorphic xanthoastrocytoma and pleomorphic xanthoastrocytoma groups.

RESULTS: Anaplastic pleomorphic xanthoastrocytoma was more likely to demonstrate high-grade features than pleomorphic xanthoastrocytoma, including greater maximum tumor diameter $(4.7 \pm 0.6 \mathrm{~cm}$ versus $3.1 \pm 1.1 \mathrm{~cm}, P=.001)$, more frequent heterogeneous contrast enhancement of solid portions ( $88.9 \%$ versus $20.0 \%, P=.01$ ), more obvious peritumoral edema $(2.3 \pm 0.9 \mathrm{~cm}$ versus $1.0 \pm 0.9 \mathrm{~cm}, P=.008)$, lower minimum relative ADC on DWI (1.0 \pm 0.2 versus $1.5 \pm 0.4, P=.008)$, and higher maximum relative CBV on DSC-PWI ( $2.6 \pm 0.8$ versus $1.6 \pm 0.2, P=.036)$.

CONCLUSIONS: Anaplastic pleomorphic xanthoastrocytomas often have more aggressive MR imaging features mimicking high-grade astrocytomas than pleomorphic xanthoastrocytomas. DWI and DSC-PWI might be useful in the characterization and differentiation of anaplastic pleomorphic xanthoastrocytoma and pleomorphic xanthoastrocytoma.

ABBREVIATIONS: $\mathrm{APXA}=$ anaplastic pleomorphic xanthoastrocytoma; $\mathrm{PXA}=$ pleomorphic xanthoastrocytoma; $r \mathrm{ADC} \mathrm{C}_{\min }=$ minimum relative $\mathrm{ADC} ; \mathrm{rCBV}_{\max }=$ maximum relative $\mathrm{CBV} ; \mathrm{WHO}=$ World Health Organization

$\mathbf{P}$ eomorphic xanthoastrocytoma (PXA) is a rare circumscribed glioma composing $<1 \%$ of all astrocytic tumors, usually occurring in children and young adults. ${ }^{1}$ It was first described in 1979 by Kepes et $\mathrm{al}^{2}$ and was recognized as a distinct brain tumor

Received November 20, 2017; accepted after revision April 18, 2018.

From the Departments of Radiology (D.S., J.L., Z.X., D.C.) and Pathology (Y.Z.), First Affiliated Hospital of Fujian Medical University, Fuzhou, P.R. China; and Siemens Healthcare Ltd (Z.Z.), Shanghai, P.R. China

The first two authors contributed equally to this study.

This work was supported by the Leading Project of the Department of Science and Technology of Fujian Province (No. 2016 Y0042)

Please address correspondence to Dairong Cao, MD, Department of Radiology, First Affiliated Hospital of Fujian Medical University, 20 Cha-Zhong Rd, Fuzhou, Fujian 350005, P.R. China; e-mail: dairongcao@163.com

-- Indicates open access to non-subscribers at www.ajnr.org

http://dx.doi.org/10.3174/ajnr.A5701 by the World Health Organization (WHO) in 1993. ${ }^{3}$ Although PXA was classified as a WHO grade II tumor, "PXA with anaplastic features" composes $15 \%-50 \%$ of these lesions. ${ }^{4-7}$ The 2016 WHO classification system has divided PXA into 2 distinct entities based on histopathologic features: WHO grade II PXA and WHO grade III anaplastic PXA (APXA). ${ }^{8,9}$ The APXA is defined as the presence of $\geq 5$ mitoses per 10 high-power fields. Only gross total resection may be performed for the patients with PXA, whereas attempted gross total resection and adjuvant therapies are required for the patients with APXA. ${ }^{5,10}$ Furthermore, APXA has been reported to have a worse prognosis than PXA, with 5-year overall survival of 57.1\%. ${ }^{5,11}$ Therefore, preoperative differentiation between the 2 entities by MR imaging may aid in planning the treatment strategy and predicting prognosis.

APXA is associated with histopathologic features of malignancy, such as increased mitotic activity, necrosis, or endothelial 
proliferation. ${ }^{12,13}$ Some studies have reported the characteristic MR imaging appearances of PXA ${ }^{14-20}$ but did not separate the imaging characteristics of APXA from PXA. Previously, only a few case reports or small case series were available regarding the MR imaging features of APXA, which demonstrated intense heterogeneous enhancement with severe peritumoral edema. ${ }^{20-26}$ Moreover, Moore et $\mathrm{al}^{14}$ reported a patient with APXA who underwent diffusion-weighted MR imaging showing diffusion restriction, indicating that DWI may be potentially useful for the characterization of APXA. To the best of our knowledge, conventional and advanced MR imaging for APXA have not been systematically reported. Therefore, the purpose of this study was to investigate the conventional and advanced MR imaging features of APXA and PXA to determine whether there are any differences in imaging characteristics between these 2 tumors.

\section{MATERIALS AND METHODS Study Population}

This retrospective study was approved by the institutional review board, and the requirement of written informed consent was waived. We collected 19 consecutive patients who underwent preoperative MR imaging for a pathologically proved APXA $(n=9)$ or PXA $(n=10)$ in our hospital between January 2008 and November 2017. The MR imaging and clinical records of these patients were analyzed.

\section{Histopathologic Diagnosis}

All cases were reviewed on the basis of the histologic features by a neuropathologist (15 years of experience in neuropathology) according to the 2016 WHO classification of central nervous system tumors. The diagnostic criteria included tumors demonstrating a relatively solid growth pattern, composed of spindle-shaped, pleomorphic, and multinucleated cells, associated with both pale and bright eosinophilic granular bodies to be diagnosed as PXA. Anaplastic features, which included a mitotic index of $\geq 5$ of 10 high-power fields with or without necrosis and endothelial proliferation, were diagnosed as APXA.

\section{Preoperative MR Imaging Techniques}

All patients underwent MR imaging on 3T scanners (Magnetom Verio or Magnetom Skyra; Siemens, Erlangen, Germany) or a 1.5T scanner (Signa TwinSpeed; GE Healthcare, Milwaukee, Wisconsin). The retrospective nature of this study resulted in variability in MR images and imaging protocols. Conventional MR imaging protocols included an axial T2-weighted sequence, nonenhanced axial and sagittal T1-weighted sequences, and 3 orthogonal plane contrast-enhanced T1-weighted sequences. An FOV of $22 \mathrm{~cm}^{2}$, imaging matrix of $256 \times 256$, and slice thickness of $5 \mathrm{~mm}$ were uniformly applied in all sequences.

DWI was performed in 9 patients with PXA and 8 patients with APXA using an axial echo-planar sequence according to following technique parameters: TR/TE $=8200 / 102 \mathrm{~ms}$, FOV $=$ $22 \times 22 \mathrm{~cm}$, section thickness $/$ gap $=5 \mathrm{~mm} / 1 \mathrm{~mm}$, diffusion gradient encoding $=b=0,1000 \mathrm{~s} / \mathrm{mm}^{2}$. The diffusion gradient was used in 3 orthogonal directions. ADC maps were automatically calculated using a monoexponential model.

Dynamic susceptibility contrast-enhanced perfusion-weighted im- aging was available in 4 patients with PXA and 5 patients with APXA. DSC-PWI was performed with a $\mathrm{T} 2{ }^{*}$-weighted gradient recalled echo-planar imaging sequence during the intravenous power injection of $0.1 \mathrm{mmol} / \mathrm{kg}$ of gadopentetate dimeglumine or gadobenate dimeglumine at a flow rate of $5 \mathrm{~mL} / \mathrm{s}$. The parameters of DSC-PWI were as follows: TR/TE $=1000-1250 / 54$ $\mathrm{ms} ; \mathrm{FOV}=22 \times 22 \mathrm{~cm}$; section thickness $/$ gap $=5 \mathrm{~mm} / 1 \mathrm{~mm}$. The CBV maps were generated with a single-compartment model and an automated arterial input function, as described in our previous study. ${ }^{27}$

\section{MR Imaging Analysis}

All images were reviewed in consensus by 2 radiologists (readers 1 and 2 with 20 and 8 years of experience in neuroimaging, respectively) to make a factual comparison and minimize the confounding effects. The readers were blinded to tumor histology and recorded the following tumor characteristics: 1) tumor location (frontal, occipital, temporal, or parietal; superficial or deep); 2) tumor size (largest diameter, in centimeters); 3) the presence of cystic degeneration; 4) enhancement characteristics of the solid component (heterogeneous or homogeneous); 5) the presence and degree of peritumoral edema (largest diameter, in centimeters); 6) leptomeningeal contact; and 7) the presence of restricted diffusion, defined as high signal on DWI and corresponding low signal on ADC maps compared with contralateral normal brain parenchyma. Tumor size was defined as the largest diameter measured on contrast-enhanced T1WI. The peritumoral edema was defined as the nonenhanced, T2-hyperintense regions surrounding the enhancing tumors on contrast-enhanced T1WI. The tumor location was defined as the main lobe involvement when $>1$ lobe was involved.

When DWI or DSC-PWI examinations were available, another experienced radiologist (reader 3 with 4 years of experience in neuroimaging) blinded to tumor histopathology evaluated the ADC maps and CBV maps separately. The ADC values of tumor were calculated by placing an ROI inside the solid components of the tumor on the ADC maps. Three nonoverlapping ROIs (20-30 $\mathrm{mm}^{2}$ ) were manually placed inside the solid components of the tumor on the ADC maps where the tumor showed relatively low signal. The minimum ADC values were taken into account. In 2 tumors with smaller solid components or obvious hemorrhage, only 1 ROI could be placed on the enhancing portions of the tumor. The ROI placement was made from the contrast-enhancing solid components of the tumor, avoiding cystic, hemorrhagic, or apparent vascular structures that might influence the ADC values. To minimize variances of ADC values in an individual patient, we placed a single ROI inside the contralateral normal-appearing brain parenchyma on ADC maps. CBV measurements were performed with the same ROI as used for ADC measurements, and the maximum CBV values were considered. Tumor/parenchyma minimum relative ADC ratios $\left(\mathrm{rADC}_{\text {min }}\right)$ and maximum relative $\mathrm{CBV}$ ratios $\left(\mathrm{rCBV}_{\max }\right)$ were calculated.

\section{Statistical Analysis}

The normality of all continuous parameters was initially assessed using the Kolmogorov-Smirnov test. The Fisher exact test was 
Table 1: The demographic data and conventional MR imaging characteristics of PXA and APXA

\begin{tabular}{|c|c|c|c|}
\hline & $\begin{array}{c}\text { PXA } \\
(n=10)\end{array}$ & $\begin{array}{l}\text { APXA } \\
(n=9)\end{array}$ & $\begin{array}{c}P \\
\text { Value }\end{array}$ \\
\hline \multicolumn{4}{|l|}{ Clinical data } \\
\hline Male sex (No.) (\%) & $6(46.2 \%)$ & $4(44.4 \%)$ & .604 \\
\hline Mean age (yr) & $32.8 \pm 22.3$ & $47.7 \pm 11.7$ & .09 \\
\hline Location (No.) & & & .905 \\
\hline Frontal lobe & 2 & 2 & \\
\hline Temporal lobe & 5 & 3 & \\
\hline Occipital lobe & 1 & & \\
\hline Parietal lobe & 2 & 3 & \\
\hline Superficial location (No.) (\%) & $9(90 \%)$ & $8(88.9 \%)$ & .720 \\
\hline \multicolumn{4}{|l|}{ Conventional MR imaging } \\
\hline Mean size $(\mathrm{cm})$ & $3.1 \pm 1.1$ & $4.7 \pm 0.6$ & .001 \\
\hline $\begin{array}{l}\text { Presence of cystic degeneration } \\
\text { (No.) (\%) }\end{array}$ & $7(70.0 \%)$ & $8(88.9 \%)$ & .497 \\
\hline Peritumoral edema (mean) (cm) & $1.0 \pm 0.9$ & $2.3 \pm 0.9$ & .008 \\
\hline $\begin{array}{l}\text { Heterogeneous enhancement } \\
\text { (No.) (\%) }\end{array}$ & $2(20.0 \%)$ & $8(88.9 \%)$ & .01 \\
\hline $\begin{array}{l}\text { Leptomeningeal contact } \\
\text { (No.) (\%) }\end{array}$ & $9(90 \%)$ & $7(77.8 \%)$ & .661 \\
\hline
\end{tabular}

Table 2: Comparison of the PXA and APXA groups regarding the variables of interest ${ }^{\mathrm{a}}$

\begin{tabular}{lccc}
\hline & PXA & APXA & P Value \\
\hline $\operatorname{rADC}_{\text {min }}(n=17)$ & $1.5 \pm 0.4$ & $1.0 \pm 0.2$ & .008 \\
$\mathrm{rCBV}_{\text {max }}(n=9)$ & $1.6 \pm 0.2$ & $2.6 \pm 0.8$ & .036 \\
\hline a
\end{tabular}
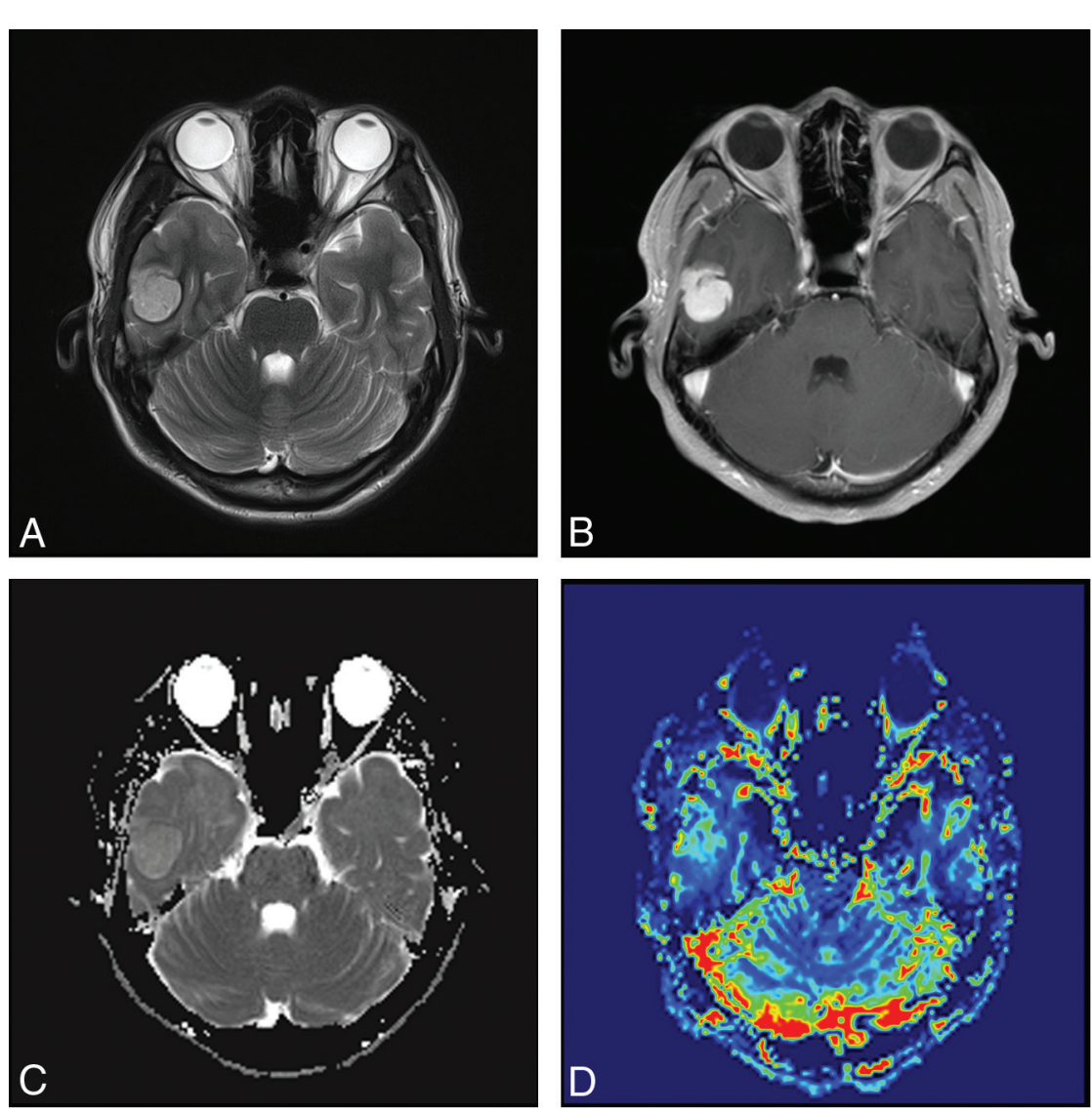

FIG 1. A 24-year-old male patient with pleomorphic astrocytoma. T2WI (A) and contrast-enhanced TTWI (B) show a homogeneous contrast-enhancing solid tumor without perilesional edema located in the temporal lobe. $C, A$ correlative $A D C$ map shows the tumor with an elevated $A D C$ value $\left(r A D C_{\min }=1.5\right)$. $D, A$ corresponding color $C B V$ image shows significantly increased perfusion with the calculated $\mathrm{rCBV}_{\max }$ of 1.6 . used to assess the differences in the categoric variables (age, sex, location, cystic degeneration, enhancement characteristics, leptomeningeal contact, and the presence of restricted diffusion) between the PXA and APXA groups. The Mann-Whitney $U$ test was used to assess the differences in continuous variables (edema and size) between the PXA and APXA groups because of a lack of normality of the data. The Student $t$ test was used to assess the differences for $\mathrm{rCBV}_{\max }$ and $\mathrm{rADC}_{\min }$ parameters between the 2 groups. Statistical analysis was performed with the Statistical Package for the Social Sciences (SPSS 22.0 Version for Windows; IBM, Armonk, New York). $P$ values $<.05$ indicated statistical significance.

\section{RESULTS}

\section{Demographic Data and Conventional MR Imaging}

The demographic data and MR imaging features are summarized in Table 1. All 19 tumors were in the supratentorial region. Eight APXAs (8/9, 88.9\%) and 9 PXAs (9/10, 90\%) were superficial (on the surface of the brain parenchyma). There was no significance in the tumor location between PXA and APXA groups.

On the preoperative imaging, the lesion was significantly larger in patients with APXA than in those with PXA $(4.7 \pm 0.6 \mathrm{~cm}$ versus $3.1 \pm 1.1 \mathrm{~cm}, P=.001)$. Peritumoral edema was observed in 7 PXA cases and 9 APXA cases, respectively. Eight patients with APXA $(8 / 9,88.9 \%)$ and 4 with PXA $(4 / 10,40.0 \%)$ had obvious peritumoral edema (defined as $>1 \mathrm{~cm}$ in diameter). The maximum diameter of peritumoral edema in the APXA group was significantly larger than that in the PXA group $(P=.008)$. The presence of heterogeneous enhancement of solid portions was observed less frequently in patients with PXA than in those with APXA (2/10 versus $8 / 9, P=.01$ ). Leptomeningeal contact was seen in 7 APXA cases and 9 PXA cases.

\section{Advanced MR Imaging Findings}

Table 2 summarizes the findings of 17 cases with DWI and 9 cases with DSCPWI. Compared with contralateral normal brain parenchyma, relatively high signal intensity on DWI was more likely to be present in cases with APXA (5/8, $62.5 \%)$ than in those with PXA (1/9, $11.1 \%)(P=.027)$. Moreover, the $\mathrm{rADC}_{\text {min }}$ values of APXA were significantly lower than those of PXA (1.0 \pm 0.2 versus $1.5 \pm 0.4 ; P=.008)$. On CBV maps, the $\mathrm{rCBV}_{\max }$ values of APXA were significantly higher than those of PXA $(2.6 \pm 0.8$ versus $1.6 \pm 0.2 ; P=.036)$. Representative cases are shown in Figs 1-3.

Table 3 summarizes the MR imaging findings of APXA previously reported in the literature. ${ }^{20-26,28-35}$ 

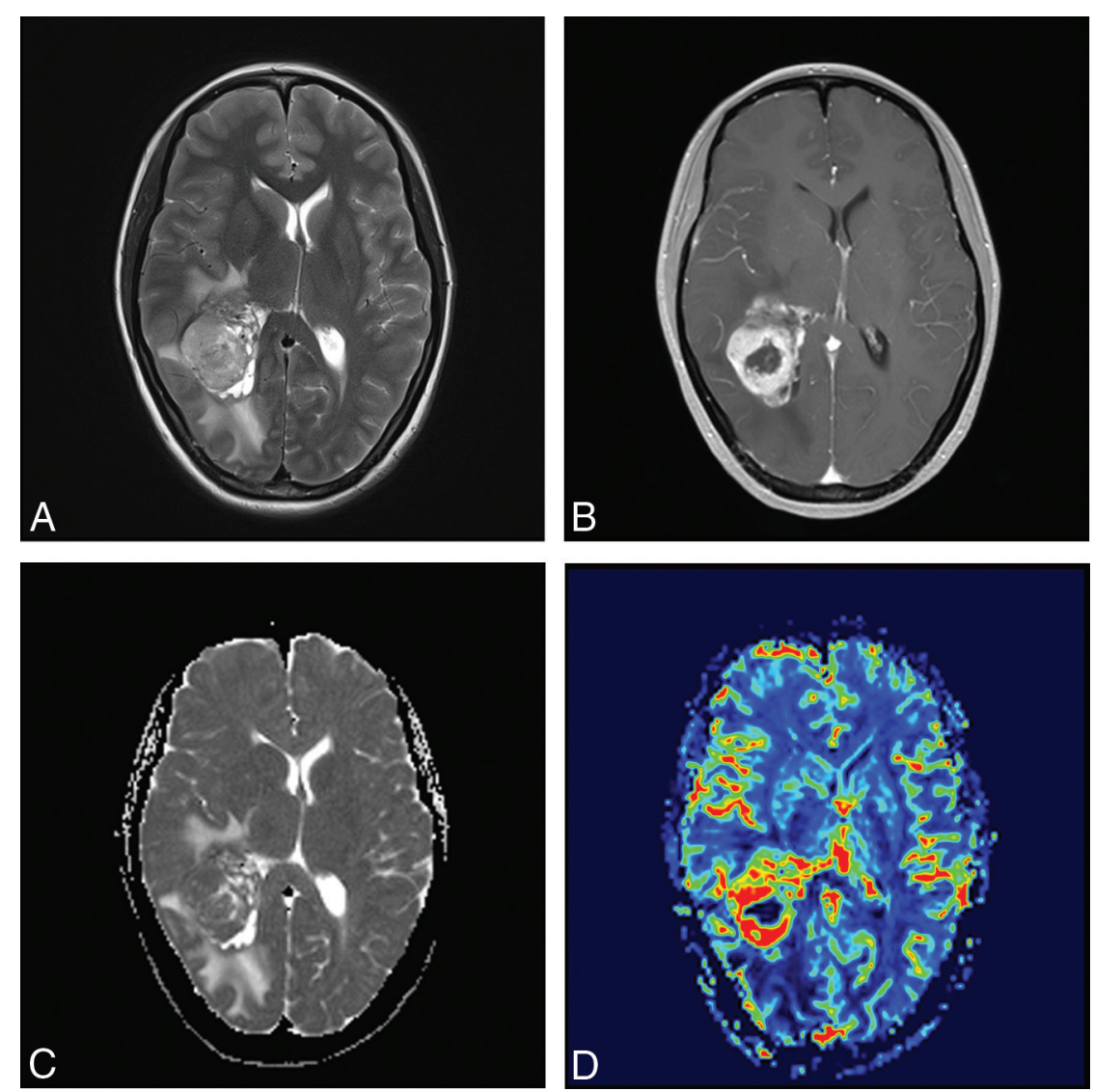

FIG 2. A 41-year-old female patient with anaplastic pleomorphic astrocytoma. T2WI (A) and contrast-enhanced TIWI $(B)$ show a heterogeneous contrast-enhancing tumor with marked perilesional edema located in the occipital lobe. $C$, A correlative ADC map shows the lesion with a decreased $A D C$ value $\left(r A D C_{\min }=0.97\right)$. $D, A$ corresponding color $C B V$ image shows significantly increased perfusion with a calculated $\mathrm{rCBV}_{\max }$ of 4.01 .
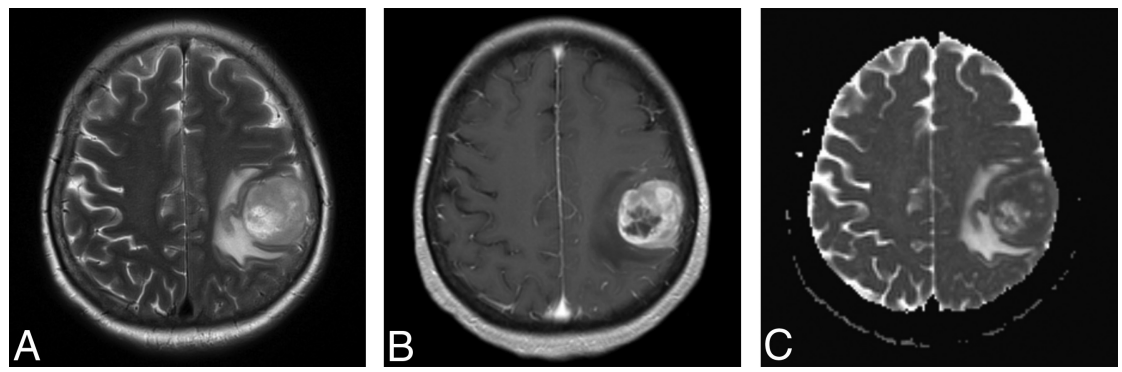

FIG 3. A 68-year-old female patient with anaplastic pleomorphic astrocytoma. T2WI $(A)$ and contrast-enhanced TIWI $(B)$ show a heterogeneous contrast-enhancing tumor with marked perilesional edema located in the parietal lobe. $C$, A correlative ADC map shows the lesion with diffusion restriction $\left(r A D C_{\min }=0.92\right)$.

\section{DISCUSSION}

Our results show that APXA had MR imaging features similar to those of other high-grade astrocytomas, namely more heterogeneous contrast enhancement, obvious peritumoral edema, lower $\mathrm{rADC}_{\text {min }}$ ratio on DWI, and higher $\mathrm{rCBV}_{\max }$ ratio on DSC-PWI.

According to the 2016 WHO classification of the central nervous system, PXA is classified as a grade II astrocytoma histologically. ${ }^{8}$ Previous studies have found that PXAs may undergo spontaneous malignant transformation into high-grade gliomas across time without any treatment. ${ }^{12,22,36}$ In a study of the histologic evolution of the PXA, an abrupt transition from a typical PXA without mitoses to a clearly high-grade tumor was found in a repeat biopsy during long follow-up, which was considered a secondary malignant change on a pre-existing PXA. ${ }^{36}$ Thus, APXA (grade III astrocytoma) is more likely to be derived from a previous PXA with the development of anaplastic histologic features. In the present study, APXA accounted for $47.4 \%$ of the cases, which is much higher than the number previously reported by Giannini et al. ${ }^{7}$ However, the results reported by Hirose et $\mathrm{al}^{6}$ were that about $50 \%$ of PXAs showed anaplastic features, findings comparable with those in our study.

PXA most frequently occurred in children and young adults in our study, consistent with previous studies. ${ }^{1,5,37}$ In contrast, 6 of 9 patients with APXA were middle-aged adults (40-65 years of age) with a mean age of 47.7 years at their first presentation, which was discordant with previous studies. ${ }^{37}$ It has been reported that high-grade astrocytomas, including anaplastic astrocytoma and glioblastoma, were more common in older adults with a median age of 56-64 years. ${ }^{38-40}$ However, most of the patients with APXA in our series were middle-aged adults and tended to be younger than those with other highgrade astrocytomas.

PXA is an overwhelming, superficial supratentorial tumor with a predilection for the temporal lobe. Previous studies reported that PXA occurred rarely in the cerebellum, ${ }^{37}$ hypothalamus, ${ }^{41}$ quadrigeminal plate, ${ }^{41}$ or pineal gland. ${ }^{42}$ Similar to PXA, almost all APXA tumors in our series showed a superficial location in the cerebral hemispheres with involvement of the superficial cortex and leptomeninges. Both PXA and APXA are believed to develop from subpial astrocytes, which partly explains why these 2 tumors preferably arise from superficial cortical sites. ${ }^{2}$ Our findings demonstrate that a superficial location with leptomeningeal contact was a frequent feature of APXA and PXA. In addition, our results show that the common tumor location of PXA was the temporal lobe $(50.0 \%)$, which is in keeping with findings in previous studies. $^{16,17}$

Conventional MR imaging can provide useful information regarding tumor size, contrast enhancement, peritumoral edema, necrosis, hemorrhage, and cystic degeneration, which are all helpful in characterizing tumor aggressiveness and evaluating tumor grading. In our study, we found that APXA had significantly 
Table 3: Summary of MR imaging findings of APXA previously reported in the literature

\begin{tabular}{|c|c|c|c|c|c|c|c|c|}
\hline No. & Author (Year) & $\begin{array}{c}\text { Age (yr)/ } \\
\text { Sex }\end{array}$ & Location & Size $(\mathrm{cm})$ & $\begin{array}{l}\text { Imaging } \\
\text { Pattern }\end{array}$ & Enhancement & $\begin{array}{c}\text { Peritumoral } \\
\text { Edema }\end{array}$ & $\begin{array}{c}\text { Well- } \\
\text { Circumscribed }\end{array}$ \\
\hline 1 & Tekkök and Sav (2004) ${ }^{22}$ & $13 / \mathrm{M}$ & Frontal & - & Solid-cystic & Heterogeneous/intense & Severe & - \\
\hline 2 & Lubansu et al (2004) & $7 / \mathrm{F}$ & Temporal & 6 & Solid-cystic & Heterogeneous/intense & Severe & + \\
\hline 3 & Chang et al $(2006)^{24}$ & $4 / F$ & Cerebellar vermis & & Solid-cystic & Heterogeneous/intense & - & + \\
\hline 4 & Nakajima et al $(2006)^{25}$ & $31 / F$ & Temporal & - & Solid & Heterogeneous/intense & - & + \\
\hline 5 & Koga et al $(2009)^{28}$ & $47 / F$ & Frontal & 6 & Solid & Homogeneous/intense & Severe & + \\
\hline 6 & Okazaki et al (2009) ${ }^{29}$ & $5 / \mathrm{M}$ & Frontal-temporal & - & Solid & Homogeneous/intense & - & + \\
\hline 7 & Fu et al $(2010)^{26}$ & $52 / \mathrm{M}$ & Ventricle & - & Cystic-solid & Heterogeneous/intense & - & + \\
\hline 8 & Tsutsumi et al $(2010)^{30}$ & $16 / \mathrm{F}$ & Temporal & 6 & Solid & Homogeneous/intense & - & + \\
\hline 9 & Vu et al $(2012)^{31}$ & $50 / \mathrm{M}$ & Temporal & 2.7 & Solid-cystic & Heterogeneous/intense & Severe & + \\
\hline 10 & Lim et al $(2013)^{20}$ & $37 / F$ & Corpus callosum & 4 & Cystic & - & Severe & + \\
\hline 11 & & $60 / \mathrm{F}$ & Corpus callosum & 4.8 & Solid & Intense & Severe & + \\
\hline 12 & & $53 / F$ & Temporal & 3.6 & Solid & Intense & Severe & + \\
\hline 13 & Montano et al $(2013)^{32}$ & $22 / \mathrm{M}$ & Multicentric & - & Solid & Without enhancement & Mild & - \\
\hline 14 & Benjamin et al $(2015)^{33}$ & $65 / M$ & Temporal & 3.7 & Cystic-solid & Heterogeneous/intense & - & + \\
\hline 15 & Patibandla et al $(2016)^{21}$ & $35 / M$ & Frontal & - & Solid & Heterogeneous/intense & Severe & - \\
\hline 16 & Choudry et al $(2016)^{34}$ & $55 / \mathrm{M}$ & Temporal & 2.2 & Solid & Heterogeneous/intense & Mild & + \\
\hline 17 & Thara et al $(2017)^{35}$ & $42 / \mathrm{M}$ & Temporal & 8 & Solid & Mild & Mild & + \\
\hline
\end{tabular}

Note:- + indicates yes; -, no.

greater tumor size than PXA, which may be due to the relatively high proliferative potential of APXA. Previous case reports demonstrated that APXA showed intense heterogeneous enhancement and obvious peritumoral edema on conventional MR imaging. ${ }^{21,34}$ In our study, we also found that all except 1 APXA showed heterogeneous contrast enhancement with marked peritumoral edema. In contrast, only 2 PXA cases showed heterogeneous enhancement, and 3 cases had marked peritumoral edema. The enhancement pattern of APXA could be explained by the presence of necrosis, hemorrhage, and vascular proliferation within the tumor, which was observed in most APXAs by Rutkowski et al. ${ }^{11}$ Additionally, our cohort showed results similar to those in a previous study for the frequency of the peritumoral edema. ${ }^{20}$ In the study of Lim et $a{ }^{20}{ }^{20}$ all PXAs with anaplastic features ( 4 cases) had severe perilesional edema, while only 1 of 18 PXAs presented with severe peritumoral edema, 6 cases had none, 8 cases had mild edema, and 3 cases had moderate edema. Our study demonstrated that the area of peritumoral edema in APXA was larger than that in PXA. Peritumoral edema was defined as nonenhancing, T2-hyperintense regions surrounding the enhancing tumors, which represented a heterogeneous mixture of infiltrative neoplastic cells and vasogenic edema in other high-grade astrocytomas. ${ }^{43,44}$ Despite appearing as a circumscribed tumor, most PXAs demonstrated infiltration into the surrounding brain. ${ }^{7}$ However, the pathology of peritumoral "edema" in APXA remains uncertain. Further pathologic investigations are required to explore whether the peritumoral edema surrounding the APXA tumor represents vasogenic edema or tumor infiltration.

DWI has been described as a useful tool for glioma grading using ADC values, which negatively correlate with cellularity and the Ki-67 labeling index in tumors. ${ }^{45-47}$ Only a few prior studies in the literature evaluated PXA and APXA using DWI. ${ }^{14}$ In a small group study of 11 children with PXA, Moore et $\mathrm{al}^{14}$ demonstrated that the mean ADC ratio of 6 PXAs, including 1 APXA, was 1.15, without statistical analysis. In the present study, we found that the signal intensity in the solid components of the APXA tended to be hyperintense relative to normal-appearing brain parenchyma on DWI. In addition, the signal intensity of APXA was significantly higher than that of PXA on DWI. The rADC ratio of PXA and APXA in our study was $1.29 \pm 0.44$, which was consistent with that in a recent study. ${ }^{14}$ To the best of our knowledge, the differences in ADC ratios between APXA and PXA have not been reported. Our study demonstrates that the rate of water diffusion of APXA, as reflected by the ADC ratio, was significantly lower than that of PXA. Compared with PXA, the association of lower ADC ratios in APXAs might be due to markedly high cellularity and a high nuclear/cytoplasmic ratio, which were also observed in other high grade astrocytomas. Therefore, our findings reveal that ADC could be a useful imaging parameter for assessing the differences between APXA and PXA based on distinct cell density and the nuclear/cytoplasmic ratio.

DSC-PWI has become an important tool in the preoperative characterization and grading of brain gliomas using rCBV values. ${ }^{48-51}$ Although many studies have reported that rCBV parameters were useful in astrocytoma grading, most of these studies failed to group APXA as a high-grade glioma or even to consider it as a separate cohort. ${ }^{51-54}$ To our knowledge, there are no studies assessing the differences in CBV values between APXA and PXA. Limited evidence suggested that the tumor vascularity of PXA was distinct from that in APXA. In a histopathologic study of PXA, ${ }^{6} 4$ of 6 APXAs showed microvascular proliferation, while no PXA exhibited this phenomenon. We found that the $\mathrm{rCBV}_{\text {max }}$ values of APXA and PXA were $2.6 \pm 0.8$ and $1.6 \pm 0.2$, respectively. The $\mathrm{rCBV}_{\text {max }}$ values of contrast-enhancing portions of APXA seemed to be higher than those of PXA. These preliminary findings may be explained by more microvascular proliferation in anaplastic lesions, resulting in an increase in the $\mathrm{CBV}$ value. ${ }^{6}$ However, the small number of patients did not allow making generalizations such as discrimination of APXA from PXA with DSC-PWI. Future investigations with emphasis on DSC-PWI of APXA and PXA may be of benefit.

In addition to the intrinsic limitations of a retrospective study, our study had several other limitations. First, the number of patients with advanced MR imaging remained limited; therefore, the conclusions should be interpreted with caution, especially for DSC-PWI. Future studies of larger cohorts with advanced MR 
imaging are necessary to generalize these findings. Second, the patients with APXA seemed to be older than those with PXA, but the difference was not significant, possibly due to the small size of this study. Hence, the difference in age may affect the values of CBV and ADC. However, these parameters of the tumors were normalized by contralateral normal-appearing brain parenchyma to reduce intersubject variance including age and sex. Third, we only focused on imaging appearances and parameters, but there is a lack of a direct pathologic correlation. Therefore, we cannot state with certainty whether the imaging parameters represent true pathophysiologic information of the tumor. Thus, further prospective study with strict pathologic validation is recommended.

\section{CONCLUSIONS}

APXA can present with more aggressive conventional and advanced MR imaging features, mimicking high-grade astrocytoma at initial diagnosis, than PXA. Greater maximum tumor diameter, heterogeneous contrast enhancement, obvious peritumoral edema, and lower $\mathrm{rADC}_{\text {min }}$ and higher $\mathrm{rCBV}_{\text {max }}$ are more common features in APXA compared with PXA. DWI and DSC-PWI might be useful in the characterization and differentiation of APXA and PXA.

\section{REFERENCES}

1. Rao AA, Laack NN, Giannini C, et al. Pleomorphic xanthoastrocytoma in children and adolescents. Pediatr Blood Cancer 2010;55: 290-94 CrossRef Medline

2. Kepes JJ, Rubinstein LJ, Eng LF. Pleomorphic xanthoastrocytoma: a distinctive meningocerebral glioma of young subjects with relatively favorable prognosis—a study of 12 cases. Cancer 1979;44: 1839-52 Medline

3. Kleihues P, Burger PC, Scheithauer BW. The new WHO classification of brain tumours. Brain Pathol 1993;3:255-68 CrossRef Medline

4. Louis DN, Ohgaki H, Wiestler OD, et al. The 2007 WHO classification of tumours of the central nervous system. Acta Neuropathol 2007;114:97-109 CrossRef Medline

5. Ida CM, Rodriguez FJ, Burger PC, et al. Pleomorphic xanthoastrocytoma: natural history and long-term follow-up. Brain Pathol 2015;25:575-86 CrossRef Medline

6. Hirose T, Ishizawa K, Sugiyama $\mathrm{K}$, et al. Pleomorphic xanthoastrocytoma: a comparative pathological study between conventional and anaplastic types. Histopathology 2008;52:183-93 Medline

7. Giannini C, Scheithauer BW, Burger PC, et al. Pleomorphic xanthoastrocytoma: what do we really know about it? Cancer 1999;85:2033-45 Medline

8. Louis DN, Perry A, Reifenberger G, et al. The $\mathbf{2 0 1 6}$ World Health Organization Classification of Tumors of the Central Nervous System: a summary. Acta Neuropathol 2016;131:803-20 CrossRef Medline

9. Wesseling P, Capper D. WHO 2016 classification of gliomas. Neuropathol Appl Neurobiol 2018;44:139-50 CrossRef Medline

10. Marton E, Feletti A, Orvieto E, et al. Malignant progression in pleomorphic xanthoastrocytoma: personal experience and review of the literature. J Neurol Sci 2007;252:144-53 CrossRef Medline

11. Rutkowski MJ, Oh T, Niflioglu GG, et al. Pleomorphic xanthoastrocytoma with anaplastic features: retrospective case series. World Neurosurg 2016;95:368-74 CrossRef Medline

12. Kahramancetin N, Tihan T. Aggressive behavior and anaplasia in pleomorphic xanthoastrocytoma: a plea for a revision of the current WHO classification. CNS Oncol 2013;2:523-30 CrossRef Medline

13. Tonse R, Gupta T, Epari S, et al. Impact of WHO 2016 update of brain tumor classification, molecular markers and clinical outcomes in pleomorphic xanthoastrocytoma. J Neurooncol 2018;136: 343-50 CrossRef Medline

14. Moore W, Mathis D, Gargan L, et al. Pleomorphic xanthoastrocy- toma of childhood: MR imaging and diffusion MR imaging features. AJNR Am J Neuroradiol 2014;35:2192-96 CrossRef Medline

15. Gonçalves VT, Reis F, Queiroz Lde S, et al. Pleomorphic xanthoastrocytoma: magnetic resonance imaging findings in a series of cases with histopathological confirmation. Arq Neuropsiquiatr 2013;71:35-39 CrossRef Medline

16. Yu S, He L, Zhuang X, et al. Pleomorphic xanthoastrocytoma: MR imaging findings in 19 patients. Acta Radiol 2011;52:223-28 CrossRef Medline

17. Crespo-Rodriguez AM, Smirniotopoulos JG, Rushing EJ. MR and CT imaging of 24 pleomorphic xanthoastrocytomas (PXA) and a review of the literature. Neuroradiology 2007;49:307-15 CrossRef Medline

18. Bucciero A, De Caro M, De Stefano V, et al. Pleomorphic xanthoastrocytoma: clinical, imaging and pathological features of four cases. Clin Neurol Neurosurg 1997;99:40-45 CrossRef Medline

19. Tien RD, Cardenas CA, Rajagopalan S. Pleomorphic xanthoastrocytoma of the brain: MR findings in six patients. AJR Am J Roentgenol 1992;159:1287-90 CrossRef Medline

20. Lim S, Kim JH, Kim SA, et al. Prognostic factors and therapeutic outcomes in 22 patients with pleomorphic xanthoastrocytoma. $J$ Korean Neurosurg Soc 2013;53:281-87 CrossRef Medline

21. Patibandla MR, Nayak M, Purohit AK, et al. Pleomorphic xanthoastrocytoma with anaplastic features: a rare case report and review of literature with reference to current management. Asian J Neurosurg 2016;11:319 CrossRef

22. Tekkök IH, Sav A. Anaplastic pleomorphic xanthoastrocytomas: review of the literature with reference to malignancy potential. $\mathrm{Pe}$ diatr Neurosurg 2004;40:171-81 CrossRef Medline

23. Lubansu A, Rorive S, David P, et al. Cerebral anaplastic pleomorphic xanthoastrocytoma with meningeal dissemination at first presentation. Childs Nerv Syst 2004;20:119-22 CrossRef Medline

24. Chang HT, Latorre JG, Hahn S, et al. Pediatric cerebellar pleomorphic xanthoastrocytoma with anaplastic features: a case of longterm survival after multimodality therapy. Childs Nerv Syst 2006;22: 609-13 CrossRef Medline

25. Nakajima T, Kumabe T, Shamoto $H$, et al. Malignant transformation of pleomorphic xanthoastrocytoma. Acta Neurochir (Wien) 2006; 148:67-71; discussion 71 CrossRef Medline

26. Fu YJ, Miyahara H, Uzuka T, et al. Intraventricular pleomorphic xanthoastrocytoma with anaplastic features. Neuropathology 2010; 30:443-48 CrossRef Medline

27. Xing Z, Yang X, She D, et al. Noninvasive assessment of IDH mutational status in World Health Organization grade II and III astrocytomas using DWI and DSC-PWI combined with conventional MR imaging. AJNR Am J Neuroradiol 2017;38:1138-44 CrossRef Medline

28. Koga T, Morita A, Maruyama K, et al. Long-term control of disseminated pleomorphic xanthoastrocytoma with anaplastic features by means of stereotactic irradiation. Neuro Oncol 2009;11:446-51 CrossRef Medline

29. Okazaki T, Kageji T, Matsuzaki K, et al. Primary anaplastic pleomorphic xanthoastrocytoma with widespread neuroaxis dissemination at diagnosis: a pediatric case report and review of the literature. J Neurooncol 2009;94:431-37 CrossRef Medline

30. Tsutsumi S, Abe Y, Yasumoto Y, et al. Anaplastic pleomorphic xanthoastrocytoma with a component of anaplastic astrocytoma presenting as skull base tumor followed by downward extracranial extension: case report. Neurol Med Chir (Tokyo) 2010;50:1108-12 CrossRef Medline

31. Vu TM, Liubinas SV, Gonzales M, et al. Malignant potential of pleomorphic xanthoastrocytoma. J Clin Neurosci 2012;19:12-20 CrossRef Medline

32. Montano N, Papacci F, Cioni B, et al. Primary multicentric anaplastic pleomorphic xanthoastrocytoma with atypical features. J Clin Neurosci 2013;20:1605-08 CrossRef Medline

33. Benjamin C, Faustin A, Snuderl M, et al. Anaplastic pleomorphic xanthoastrocytoma with spinal leptomeningeal spread at the time 
of diagnosis in an adult. J Clin Neurosci 2015;22:1370-73 CrossRef Medline

34. Choudry UK, Khan SA, Qureshi A, et al. Primary anaplastic pleomorphic xanthoastrocytoma in adults: case report and review of literature. Int J Surg Case Rep 2016;27:183-88 CrossRef Medline

35. Thara K, Sharma R, Thiagarajan G, et al. Anaplastic pleomorphic xanthoastrocytoma in a case of neurofibromatosis type 1: a case report. J Clin Diagn Res 2017;11:ED23-24 CrossRef Medline

36. Wu X, Bandopadhayay $\mathrm{P}, \mathrm{Ng}$ J, et al. The evolution of the histology in pleomorphic xanthoastrocytomas in children: a study of 15 cases. Pathology 2011;43:9-16 CrossRef Medline

37. Perkins SM, Mitra N, Fei W, et al. Patterns of care and outcomes of patients with pleomorphic xanthoastrocytoma: a SEER analysis. J Neurooncol 2012;110:99-104 CrossRef Medline

38. Ostrom QT, Gittleman H, Liao P, et al. CBTRUS statistical report: primary brain and other central nervous system tumors diagnosed in the United States in 2010-2014. Neuro Oncol 2017;19:v1-88 CrossRef Medline

39. Thakkar JP, Dolecek TA, Horbinski C, et al. Epidemiologic and molecular prognostic review of glioblastoma. Cancer Epidemiol Biomarkers Prev 2014;23:1985-96 CrossRef Medline

40. Rasmussen BK, Hansen S, Laursen RJ, et al. Epidemiology of glioma: clinical characteristics, symptoms, and predictors of glioma patients grade I-IV in the Danish Neuro-Oncology Registry. J Neurooncol 2017;135:571-79 CrossRef Medline

41. Gallo P, Cecchi PC, Locatelli F, et al. Pleomorphic xanthoastrocytoma: long-term results of surgical treatment and analysis of prognostic factors. Br J Neurosurg 2013;27:759-64 CrossRef Medline

42. Katayama K, Asano K, Shimamura N, et al. Case of pleomorphic xanthoastrocytoma with anaplastic features in the pineal gland. Brain Tumor Pathol 2013;30:242-46 CrossRef Medline

43. Barajas RF Jr, Phillips JJ, Parvataneni R, et al. Regional variation in histopathologic features of tumor specimens from treatment-naive glioblastoma correlates with anatomic and physiologic MR imaging. Neuro Oncol 2012;14:942-54 CrossRef Medline

44. Konukoglu E, Clatz O, Bondiau PY, et al. Extrapolating glioma invasion margin in brain magnetic resonance images: suggesting new irradiation margins. Med Image Anal 2010;14:111-25 CrossRef Medline
45. Sugahara T, Korogi $\mathrm{Y}$, Kochi M, et al. Usefulness of diffusionweighted MRI with echo-planar technique in the evaluation of cellularity in gliomas. J Magn Reson Imaging 1999;9:53-60 Medline

46. Zeng Q, Dong F, Shi F, et al. Apparent diffusion coefficient maps obtained from high $b$ value diffusion-weighted imaging in the preoperative evaluation of gliomas at 3T: comparison with standard b value diffusion-weighted imaging. Eur Radiol 2017;27:5309-15 CrossRef Medline

47. Higano S, Yun X, Kumabe T, et al. Malignant astrocytic tumors: clinical importance of apparent diffusion coefficient in prediction of grade and prognosis. Radiology 2006;241:839-46 CrossRef Medline

48. Price SJ, Green HA, Dean AF, et al. Correlation of MR relative cerebral blood volume measurements with cellular density and proliferation in high-grade gliomas: an image-guided biopsy study. AJNR Am J Neuroradiol 2011;32:501-06 CrossRef Medline

49. Sugahara T, Korogi Y, Kochi M, et al. Correlation of MR imagingdetermined cerebral blood volume maps with histologic and angiographic determination of vascularity of gliomas. AJR Am J Roentgenol 1998;171:1479-86 CrossRef Medline

50. Bisdas S, Kirkpatrick M, Giglio P, et al. Cerebral blood volume measurements by perfusion-weighted MR imaging in gliomas: ready for prime time in predicting short-term outcome and recurrent disease? AJNR Am J Neuroradiol 2009;30:681-88 CrossRef Medline

51. Delgado AF, Delgado AF. Discrimination between glioma grades II and III using dynamic susceptibility perfusion MRI: a meta-analysis. AJNR Am J Neuroradiol 2017;38:1348-55 CrossRef Medline

52. Law M, Yang S, Wang H, et al. Glioma grading: sensitivity, specificity, and predictive values of perfusion MR imaging and proton MR spectroscopic imaging compared with conventional MR imaging. AJNR Am J Neuroradiol 2003;24:1989-98 Medline

53. Jain R, Griffith B, Alotaibi F, et al. Glioma angiogenesis and perfusion imaging: understanding the relationship between tumor blood volume and leakiness with increasing glioma grade. AJNR Am J Neuroradiol 2015;36:2030-35 CrossRef Medline

54. Wang XC, Zhang H, Tan Y, et al. Combined value of susceptibilityweighted and perfusion-weighted imaging in assessing WHO grade for brain astrocytomas. J Magn Reson Imaging 2014;39:1569-74 CrossRef Medline 